\title{
LETTERS
}

\section{Erythrocytosis induced by sodium-glucose cotransporter-2 inhibitors}

We thank Dr. Mithoowani and colleagues for their excellent review on the investigation and management of erythrocytosis, ${ }^{1}$ which provides a comprehensive overview and approach to a common presentation encountered by hematologists and general practitioners.

One additional drug-associated cause of secondary erythrocytosis of increasing relevance in general practice is the use of sodium-glucose cotransporter-2 (SGLT2) inhibitors. With the growing use of this class of medications in Canada and, on the basis of mounting evidence for improved cardiovascular outcomes in type 2 diabetes and heart failure, SGLT2 inhibitors are worth including in the already extensive differential diagnosis for secondary erythrocytosis offered by Mithoowani and colleagues. ${ }^{1}$

At our centre, we have noted an increase in the number of referrals of patients with erythrocytosis who are also taking SGLT2 inhibitors, which often resolves when these drugs are stopped. Increases in hematocrit were noted in initial clinical trials of SGLT2 inhibitors and were thought to account, in part, for the cardioprotective effects of these medications., ${ }^{2,3}$ The physiology of SGLT2 inhibitor-induced erythrocytosis is complex and remains to be fully elucidated, but postulated mechanisms include hemoconcentration, modulation of iron metabolism and increased erythropoietin production, as recently reported in a Canadian study. ${ }^{4}$

To date, we are aware of a total of 5 cases of severe erythrocytosis (hematocrit $>0.53$ ) attributed to SGLT2 inhibitors that have been reported in the literature, ${ }^{5-7}$ although anecdotally we suspect this number to be much higher and indeed rising. Two cases were associated with concomitant use of SGLT2 inhibitors and testosterone replacement therapy, ${ }^{6}$ a well-known cause of secondary erythrocytosis. Another case report detailed an SGLT2 inhibitor that "unmasked" underlying polycythemia vera. ${ }^{5}$ To prevent overuse of laboratory resources, we would caution against routine investigation for polycythemia vera in patients with erythrocytosis who are taking SGLT2 inhibitors. The stepwise approach advocated by Mithoowani and colleagues ${ }^{1}$ will help to mitigate overinvestigation.

Where possible, and if alternate agents are available, we would consider stopping SGLT2 inhibitors in cases of severe erythrocytosis in consultation with other members of the medical team as an important diagnostic and therapeutic step in the approach to erythrocytosis.

\section{Benjamin Chin-Yee MD MA}

Clinical fellow, Division of Hematology,

Department of Medicine, Western

University, London, Ont.

\section{Ziad Solh MD MSc}

Assistant professor, Pathology and Laboratory Medicine, Western University, London, Ont.

\section{Cyrus Hsia MD}

Associate professor, Division of Hematology, Department of Medicine, Western University, London, Ont.

Cite as: CMAJ 2020 October 19;192: E1271. doi: $10.1503 / \mathrm{cmaj} .76686$

\section{References}

1. Mithoowani S, Laureano M, Crowther MA, et al. Investigation and management of erythrocytosis. CMAJ 2020;192:E913-8.

2. Zinman B, Wanner C, Lachin JM, et al. Empagliflozin, cardiovascular outcomes, and mortality in type 2 diabetes. N Engl J Med 2015;373:2117-28.

3. Inzucchi SE, Zinman B, Fitchett D, et al. How does empagliflozin reduce cardiovascular mortality? Insights from a mediation analysis of the EMPA-REG OUTCOME trial. Diabetes Care 2018; 41:356-63.

4. Mazer CD, Hare GMT, Connelly PW, et al. Effect of empagliflozin on erythropoietin levels, iron stores, and red blood cell morphology in patients with type 2 diabetes mellitus and coronary artery disease. Circulation 2020;141:704-7.

5. Das L, Bhansali A, Walia R. Unmasking and aggravation of polycythemia vera by canagliflozin. Diabet Med 2018;35:1613-6.

6. Motta G, Zavattaro M, Romeo F, et al. Risk of erythrocytosis during concomitant testosterone and SGLT2-inhibitor treatment: a warning from two clinical cases. J Clin Endocrinol Metab 2019; 104:819-22.

7. Gupta R, Gupta A, Shrikhande M, et al. Marked erythrocytosis during treatment with sodium glucose cotransporter-2 inhibitors-report of two cases. Diabetes Res Clin Pract 2020;162:108127.

Competing interests: None declared. 